\title{
Article
}

\section{Devising a consensus definition and framework for non-technical skills in healthcare to support educational design: A modified Delphi study}

Gordon, Morris, Baker, Paul, Darbyshire, Daniel, Catchpole, Ken and Schocken, Dawn

Available at http://clok.uclan.ac.uk/12404/

Gordon, Morris ORCID: 0000-0002-1216-5158, Baker, Paul, Darbyshire, Daniel, Catchpole, Ken and Schocken, Dawn (2014) Devising a consensus definition and framework for non-technical skills in healthcare to support educational design: A modified Delphi study. Medical Teacher, 37 (6). pp. 572-577.

It is advisable to refer to the publisher's version if you intend to cite from the work.

For more information about UCLan's research in this area go to http://www.uclan.ac.uk/researchgroups/ and search for <name of research Group>.

For information about Research generally at UCLan please go to http://www.uclan.ac.uk/research/

All outputs in CLoK are protected by Intellectual Property Rights law, including Copyright law. Copyright, IPR and Moral Rights for the works on this site are retained by the individual authors and/or other copyright owners. Terms and conditions for use of this material are defined in the policies page. 


\section{Devising a consensus definition and framework for non-technical skills in healthcare to support educational design: A modified Delphi study}

Morris Gordon, MBChB, MMed, PHD, FHEA, FACAdmed, Paul Baker MBChB, FRCP, PGDip (Med), Ken Catchpole PHD, Daniel Darbyshire MBBS MRCS PGDip (MEd) FHEA and Dawn Schocken, MPH

Morris Gordon is a Consultant Paediatrician in Blackpool Victoria Hospital (UK) and the Head of Research Studies and Transition at the Medical School, University of Central Lancashire (UK)

Paul Baker is a Consultant Geriatrician in Royal Bolton Hospital (UK) and the head of the North West Foundation School (UK)

Daniel Darbyshire is an Emergency Medicine trainee in the North West Deanery (UK) and is currently completing a Masters Degree in Medical Education with the University of Dundee

Ken Catchpole is a human factors research practitioner and Director of Surgical Safety and Human Factors Research at Cedars-Sinai Medical Center, Los Angeles.

Dawn M Schocken is the Director for the Center for Advanced Clinical Learning at the University of South Florida Morsani College of Medicine in Tampa, FL

\section{Corresponding Author:}

Morris Gordon

School of Medicine and Dentistry

Allen Building,

University of Central Lancashire,

Fylde Road,

Preston,

Lancashire,

PR1 2HE

Email: morris@betterprescribing.com 


\begin{abstract}

\section{Background}

Non-technical skills are a subset of human factors that focus on the individual and promote safety through teamwork and awareness. There is no widely adopted competency or outcome based framework for non-technical skills training in healthcare outside the surgical environment. The authors set out to devise such a framework and reach a consensus on a definition using a modified Delphi approach.
\end{abstract}

\title{
Methods
}

An exhaustive list of published and team suggested items was presented to the expert panel for ranking and to propose a definition. In the second round, a focused list was presented, as well as the proposed definition elements. The finalised framework was sent to the panel for review.

\section{Summary of results}

16 experts participated (58\% response rate). A total of 36 items of 105 ranked highly enough to present in round two. The final framework consists of 16 competencies for all and 8 specific competencies for team leaders. The consensus definition describes non-technical skills as 'a set of social (communication and team work) and cognitive (analytical and personal behaviour) skills that support high quality, safe, effective and efficient inter-professional care within the complex healthcare system’.

\section{Conclusions}

The authors have produced a new competency framework, through the works of an international expert panel, which is not discipline specific. This consensus competency framework can be used by curriculum developers, educational innovators and clinical teachers to support developments in the field. 
Attitudes to health care errors began to change towards the later end of the $20^{\text {th }}$ century with a string of high profile incidents and the publishing of a landmark report in the USA, 'To Err is Human: Building a Safer Health System,1 was pivotal in organising this movement. Key to this shift was the acceptance that human errors do occur and will always occur ${ }^{2}$, but that certain techniques can target and reduce avoidable errors ${ }^{3}$.

\section{Introduction}

The catastrophic consequences of human errors remain challenging for healthcare professions to address. To a certain extent the 'person' approach to error - removing, blaming, retraining or enacting legal or other punitive procedures on those who make errors - still remains prevalent in error reduction strategies in healthcare even though it has been thoroughly discredited ${ }^{4,5}$. For example, in the most recent high profile UK investigation $^{6}$, the person centred approach to future error reduction was key in the recommendations made. However, this approach does not acknowledge that accidents cannot be avoided by 'trying harder', belying the complexity of error causation ${ }^{3,7}$, which reinforces aberrant and risky behaviour ${ }^{8,9}$ limiting usefulness ${ }^{10}$, and rather than revealing systems problems, encourages people not to get caught making errors, leaving systems vulnerable to the repeated accidents ${ }^{11,12}$. Consequently, errors still occur with surprising frequency ${ }^{13}$.

The alternative approach is to examine the contexts and situations in which errors happen, and the conditions that allow those errors to lead to harm. Human Factors Engineering is a discipline of psychology that that has helped in the development and improvement of safety in other industries for many years ${ }^{14}$. By identifying environments, technologies, processes and systems of work which encourage errors and lead to harm ${ }^{3}$, it is possible to redesign those systems to be safer from the outset. Work to apply human factors in healthcare to enhance systems and environments has shown the potential to enhance safety ${ }^{15}$.

One human factors approach that has been successfully applied focuses on developing the generic social and cognitive skills required for effective and safe performance in a manner that is mindful of a wider systems understanding of the health care process ${ }^{16}$. 
It is possible to embed the successful approaches of teamwork and other cultural improvements, such as checklists, into an educational approach by building these 'non-technical skills' into education ${ }^{17}$. Whilst there are several frameworks for the assessment and validation of non-technical skills, there has been limited attention to questions such as 'how', 'why', 'when' and 'for whom' such education might be beneficiaries ${ }^{18}$. Indeed, the nature of the educational approach is conspicuous by its absence, with little mention of pedagogy or learning outcomes.

There is often a focus on a heterogeneous set of skills (e.g. communication, team working) or techniques (e.g. simulation) ${ }^{19-24}$. This renders them of limited practical value to clinical teachers and health professional educators in all contexts and represents poor quality educational research ${ }^{25}$.

Our recent works have sought to extract key theoretical elements to design a model of non-technical skills learning in healthcare ${ }^{26}$ and apply this to design educational interventions ${ }^{27}$, but there is just one element of an overall package of developments that are needed to move the field forward in an educationally sound manner. A key issue that exists is a lack of consensus or clarity as to specific learning outcomes or competencies that are relevant in this area. Whilst there are a number of published works that have investigated and proposed skill frameworks ${ }^{28,29}$, these have been built in a context specific manner (within operating rooms), either from the perspective of assessment $^{30}$, which offer little assistance for educational development, or as a coaching aid for specialized roles ${ }^{31}$. All have been developed for use by those either already qualified or at a late-stage of training.

There is no generic recognised framework of non-technical skills for use by clinical educators when designing educational interventions. Without such a framework, educational interventions will continue to be variable in content, quality and effectiveness. We set out to devise such a framework using a modified Delphi approach. 


\section{Methods}

We aligned our methodology with a constructivist epistemological stance, accepting that multiple and possibly conflicting set of outcomes may exist, that are very much shaped by the learner and the content ${ }^{32}$. We used a modified Delphi process to reach an expert consensus on such outcomes.

Members of NOME SIG (Non-technical skills in medical education special interest group), an international group of educators and clinicians, who have an interest and have published works involved with non-technical skills in healthcare, were consulted. They were asked to contribute to an exhaustive list of potential items for inclusion in such a framework. A virtual roundtable discussion was run between June and September 2012 and sought to include items from all published frameworks, as well as to empirically suggest items, based on existing theoretical models ${ }^{26}$ and reviews of evidence ${ }^{18}$. Through this process, it became clear that two conceptual skill domains existed - social (communication and team working skills) and behavioural (analytical and personal behaviours). All 109 items were included in the final list, which was organised in line with these emerging categories and is presented in Appendix 1.

Members of the expert panel were recruited through several methods. Firstly, two members of NOME-SIG were recruited. Secondly, invitations were sent to all corresponding authors for published studies focussing on non-technical skills education in healthcare ${ }^{18}$. Finally, all corresponding authors for non-technical skills works within key journals were invited to take part. We considered articles from August 2011 - July 2012 identified through hand searching in the following journals: Medical Education, Medical Teacher, Postgraduate medical journal, Academic Medicine, Advances in Health Sciences Education: Theory and Practice, BMC Medical Education, British Medical Journal, Journal of the American Medical Association, Lancet, New England Journal of Medicine and Journal for the Society for Simulation in Healthcare. 
In round 1, the items identified in Appendix 1 were collated into an online questionnaire delivered through survey monkey, with a likert scale from 1 to 7 to indicate the importance of each item. Free text information could be added. Additionally, participants were asked to define non-technical skills in healthcare in a free text response. These were assembled by the authors in preparation for the next round ('round 2'), with items amended as per free text consensus responses. The list of consensus items were presented, as well as new amended items with participants asked 'yes / no' for inclusion. Additionally, expert participant definitions of nontechnical skills were broken down into 10 key consensus statements and these were presented for ranking. Once again, we collated responses and as consensus were reached on the majority of items, a final first draft of the competency framework and consensus definition was sent to participants for review.

\section{Results}

16 experts joined and participated in the panel from 30 invitations (58\% response rate), with 7 countries represented (6- UK, 5 - USA, 1 - Switzerland, 1- Ireland, 1 Germany, 1 - Portugal, 1 - Iran). The Delphi panels ran between September 2013 and January 2014. All participants completed all the questions in round 1 . This was also the case in round 2, with 100\% response in all sections of the survey. A total of 36 items of the 105 presented were deemed to have ranked highly enough to present in round two. Free text responses highlighted the importance of identifying whether skills were relevant to all or just a team leader, with several specified as the later. Additionally, 12 items were edited in line with free text feedback. Finally, 7 specific statements were synthesised from the suggested definitions of non-technical skills and presented in round 2 .

In round 2, participants were asked to state whether items should be included (yes/no) and whether they were relevant to leaders. Additionally, the definition statements were presented. Analysis of results led to a final framework consists of 16 competencies for all and 8 specific competencies for team leaders. The consensus definition produced describes non-technical skills as ‘a set of social (communication and team work) and cognitive (analytical and personal behaviour) skills that support 
high quality, safe, effective and efficient interprofessional care within the complex healthcare system'.

These final items and definition were sent out to the panel for comments. Apart for some minor grammatical suggestions, no changes were made. The final competency framework is presented in Appendix 2 and is available for download directly (address to be added).

\section{Discussion}

This competency framework has been produced through a multistage process that involved synthesis of existing published outcomes together with a roundtable brainstorming process to generate new outcomes, a Delphi process and finally the construction of a competency framework for non-technical skills learning in healthcare. The aim of this process has been to support the designing of curricula and the building of educational innovations, rather than simply supporting observation and assessment.

Unsurprisingly, many items in this framework are homologous to existing tools (Fletcher 2003, Mishra 2009). This is particularly noticeable amongst the social factors (communication and team working skills). However, the items generated under cognitive factors are novel.

Up until now, there has been no consensus on a definition or a set of generic competencies for non-technical skills learning in healthcare. The framework produced delivers such a framework. This can be applied to mixed or homogenous groups of healthcare professionals and within a variety of healthcare settings, rather than existing tools that are context specific. Whilst the methods used to produce this framework have attempted to approach the issues from a different epistemological stance, the resulting framework appears to align well with relevant and achievable targets for learning outcomes, educational interventions and assessable skills. Clearly, the nature of different competencies may require different forms of assessment, but the dissemination of this framework should allow other researchers to investigate and report their experiences in doing this. 
The lack of clear identification of competencies or outcomes for training within existing published studies in the field has been previously identified as an area of concern, leading to heterogeneity in reported teaching designs and pedagogical methods (Gordon 2013). This framework should allow researchers to use a standardised approach at the outset of their work and as such support generation of new knowledge in a more efficient manner.

This framework is not meant to be a prescriptive checklist, but a tool to support educators in considering the choices they can make and to act as a prompt to support the planning and reporting of research. In formulating the framework, an expert panel was selected that represented a range of professionals working in a vast array of educational settings. The common skill of all panel members was practical experience designing or teaching non-technical skill interventions to healthcare professionals. As such, it is hoped that the finished framework is pragmatic, grounded in the realities facing teachers and reflecting needs with the field.

This framework is not based on any new empirical works and is significantly grounded in existing published tools. The outcome of the process is nothing but opinion and the results of the process are only as valid as the opinions of the experts who formed the panel. Therefore, the framework is presented not as a final product, but in response to a need. This framework is presented for use, but also for comment, refinement and possible rejection. Future published works should use the literature to report their views on this framework to ascertain face validity and so as to allow modifications to be made. Additionally, future work could seek to establish formative validity to support learning and reliability of measurements made of learner ability using the framework.

\section{Conclusions}

This study has sought to devise an expert consensus definition and set of competencies for non-technical skills learning in all areas of healthcare. The resultant product can be used by curriculum developers, educational innovators and clinical teachers to support developments in the field. This will allow local innovations and published research to better reflect the existing body of knowledge and better allow comparable research and rapid dissemination of teaching to be completed. Future 
work is needed to critique this framework in a variety of settings and as applied for a number of purposes. 
Funding/Support : No external funding was received to support this study

Other disclosures: No relevant disclosures. Morris Gordon has received travel grants, honoraria and consultancy fees from various companies including: Vifor, warner chilcott, ferring, Abott, Norgine, Casen fleet, Nutricia and Danone. No company has had any input into the planning, execution or write up of this or any works by Morris Gordon and these represent no direct conflict of interest.

Ethical approval : This was received from the University of Salford 


\section{References}

1. Kohn LT, Corrigan JM, Donaldson MS. To err is human: building a safer health system. Washington, DC: Institute of Medicine National Academies Press; 1999.

2. Department of Health (DOH). An Organisation with a Memory (http://www.dh.gov.uk/prod consum dh/groups/dh digitalassets/@dh/@en/docu ments/digitalasset/dh 4065086.pdf). 2000. Accessed 23rd January 2013.

3. Reason J. Human error: models and management BMJ. 2000;320:768-770.

4. Berwick DM, Leape LL. Reducing errors in medicine. BMJ. 1999; 319(7203): 136137.

5. Rasmussen J. The concept of human error: Is it useful for the design of safe systems in health care? In: Vincent c \& deMoll B (Eds), Risk and safety in medicine (pp. 31-47).London: Elsevier; 1999.

6. Francis R. Report of the Mid Staffordshire NHS Foundation Trust Public Inquiry. (http://www.midstaffspublicinquiry.com/report). 2013. Accessed 13th September 2013.

7. Dekker S. Patient Safety: A human factors approach. Boca Rotan, FL: Taylor and Francis Group. 2011.

8. Hammond KR. Human judgement and social policy: Irreducible uncertainty, inevitable error, unavoidable injustice. Oxford University Press; 1996.

9. Kruger DJ, Wang XT, Wilke A. Towards the development of an evolutionarily valid domain-specific risk-taking scale. Evol Psychol. 2007;5(3):555-568

10. Rosenthal NM. The incompetent doctor: Behind closed doors. London: Open University Press; 1994. 
11. Dekker SW. Accidents are normal and human error does not exist: a new look at the creation of occupational safety. International Journal of Occupational Safety and Ergonomics. 2003;9:211-218

12. Cook RI, Woods D. Operating at the Sharp End: The Complexity of Human Error. Human Error in Medicine. Hillsdale, N.J.: Lawrence Erlbaum Associates Inc.; 1994:255-310.

13. National Patient Safety Agency (NPSA). 2012. Quarterly summaries [online] (http://www.nrls.npsa.nhs.uk/resources/collections/quarterly-data-summaries/) 2012. Accessed 13th September 2013.

14. International Ergonomics association. Definition of human factors. (http://www.iea.cc/) 2012. Accessed on 25th July 2013.

15. Carayon P., Xie A., Kianfar S. Human factors and ergonomics as a patient safety practice BMJ. 2013;Qual Saf doi:10.1136/bmjqs-2013-001812

16. Dunn EJ, Mills PD, Neily J, Crittenden MD, Carmack AL, Bagian JP. Medical team training: applying crew resource management in the Veterans Health Administration. Jt Comm J Qual Patient Saf. 2007;33:317-25

17. Haji F, Morin MP, Parker K. Rethinking programme evaluation in health professions education: beyond 'did it work?' Med Educ. 2013;47:342-351

18. Gordon M., Darbyshire D., Baker P. Educational interventions to improve patient safety: A systematic review. Med Educ. 2012;46:1042-54.

19. Blum RH., Raemer DB, Carroll JS, Felstein DM, Cooper JB. Crisis resource management training for an anaesthesia faculty: a new approach to continuing education. Med Educ. 2004;38:45-55 
20. Haller G, Morales M, Pfister R, Pfister R, Berner M., Irion O, et al. Improving interprofessional teamwork in obstetrics: a crew resource management-based training programme. J Interprof Care, 2008;22:545-8.

21. Lindamood KE, Rachwal C, Kappus L, Weinstock P, Doherty EG. Development of a neonatal intensive care multidisciplinary crisis resource training programme. Newborn Infant Nurs Rev. 2011;11:17-22.

22. Blegen MA, Sehgal N, Alldredge B, Gearhart S, Wachter R. Safety culture: multidisciplinary teamwork and communication interventions. Commun Nurs Res. 2009;42:249

23. Cox KR, Scott SD, Hall LW, Aud MA, Headrick LA, Madsen R. Uncovering differences among health professions trainees exposed to an interprofessional patient safety curriculum. Qual Manag Health Care. 2009;18:182-93

24. Jankouskas TS. Crisis resource management training: impact on team process and team effectiveness. PhD thesis. PA, USA: Pennsylvania State University; 2010.

25. Norcini JJ, Banda SS. Increasing the quality and capacity of education: the challenge for the 21st century. Med Educ. 2011;45:81-86

26. Gordon M. Building a theoretically grounded model to support the design of effective non-technical skills training in healthcare: The SECTORS model. J Contemp Med Edu, 2013;1(2):77-82

27. Gordon M. Non-technical skills training to enhance patient safety. Clin Teach. 2013;10:170-175.

28. Fletcher G, Flin R, McGeorge P, Glavin R, Maran N, Patey R. 2003. Anaesthetists' Non-Technical Skills (ANTS): evaluation of a behavioural marker system. Br J Anaesth. 90(5):580-8 
29. Mishra A, Catchpole K, McCulloch P. 2009. The Oxford NOTECHS System:

reliability and validity of a tool for measuring teamwork behaviour in the operating theatre. Qual. Saf. Health Care 2009;18;104-108

30. Centre for patient safety \& Service Quality. Observational teamwork assessment for surgery (OTAS) (https://www1.imperial.ac.uk/resources/018F4A1D-5129-444E96CF-04C524C2EA99/otas manual.pdf) 2011. Accessed on $7^{\text {th }}$ May 2014.

31. Flin R, Patey R. Non-technical skills for anaesthetists: developing and applying ANTS. Best Pract Res Clin Anaesthesiol. 2011;25(2):215-27.

32. Illing J. Chapter 24 Thinking about research In. Understanding medical education Swanwick T, Wiley and sons 2013, London 